2006-594: COMPARING STUDENT PERFORMANCE USING CALCULATORS WITH PERFORMANCE USING EXCEL (MUST YOU KNOW HOW TO RIDE A HORSE IF YOU WANT TO DRIVE A CAR?)

Charles Nippert, Widener University 


\title{
Comparing Student Performance Using Calculators with Performance Using Excel (Must You Know How to Ride a Horse If You Want to Drive a Car?)
}

\begin{abstract}
Our school offers a senior year course in engineering economics. For several years students have been allowed to take routine tests in this course by using either computers with (and) spreadsheet programs(s) or conventional interest tables and calculators. The tests are the same for both sets of students and have been constructed and graded in such a way as to render differences in performance between using spreadsheets or calculators statistically insignificant. There are however significant differences between the approaches used by students using spreadsheets and those used by students using calculators on the same questions. There are also differences in the sources of difficulty and error. This paper discusses these differences and the methodology used in creating and grading these tests. A final observation is that over a period of several years the use of spreadsheets has increased.
\end{abstract}

Introduction

At our school, Engineering Economics is taught in a conventional classroom with several one hour examinations at regular class times during the semester. There is also a final examination that is also conducted in a regular classroom at the end of the semester. Starting in the Fall of 2001, the author allowed students to use laptops during in-class tests. Students who wanted to use laptops during a test could. Those who wanted to use their calculators could continue to use them. The course content was modified to include examples of both spreadsheet and calculator methods so that both computational approaches would be taught. Also, students were told that the FE requires calculators. This paper discusses how that change has impacted teaching engineering economics at our school.

Tests were graded by the instructor as normal after allowing laptops in class. After each test, the class was told the average grades of students using laptops and of students using calculators. From the test averages students knew there was no incentive from the standpoint of grades for the use of either tool. Laptop availability was not a problem because there were a number of laptops available from the university and, many students borrowed laptops from friends. All students who used laptops used the Excel spreadsheet so in this paper I use "computer solution" and "spreadsheet solution" interchangeably.

Allowing both the use of laptops AND calculators in the same test required some revision of the test procedures. Some important considerations regarding the nature of the test questions are:

1. All tests (hour quizzes and the Final Exam) were "open book, open notes". This policy was already in place so that students could use the interest tables provided in the text. Because students already had access to notes and tables, the fact that the students could 
use laptops to store notes or crib sheets presented no perceived advantage. In 2001 the school did not have a wireless network so students were not able to use laptops to communicate.

2. Test questions were written to reduce the number of repetitive calculations.

2.1 Students were told to perform no more than two iterations on any problem requiring an iterative solution whether or not they had obtained convergence. Two iterations allows the instructor to determine if the student has the correct solution procedure but does not burden a student who is using a calculator with time consuming repetitive calculations more easily performed on a computer.

2.2 Problems which had complicated cash flows over multiple years (such as calculations of After Tax Cash Flow with depreciation and loan payments) were performed for only 1 or 2 years.

2.3 Calculations involving long time periods (more than 4 years) with many different amounts were not used.

3. Until 2004, students using laptops provided their test answers on physical media; floppy disks, CD's or flash drives provided by the instructor. After 2004, Widener a wireless network and many of the students were able to e-mail the results.

4. There was no statistical difference between the grades of students who used laptops and those who did not and the pooled results were available to the classes. Success of this policy is indicated by the following written response to a survey of students.

"In this class, the tests were structured so that doing the test with a laptop or by hand did not favor either party."

Student Acceptance of the Use of Laptops

The initial response to allowing the use of laptops during tests was positive based on one on one conversations. The percent of students using laptops increased as shown in Figure 1. The increased use of laptops indicates a growing acceptance of spreadsheet use in tests. 
Figure 1

\section{Percent of Students in Engineering Economics Using Laptops During Final Examinations}

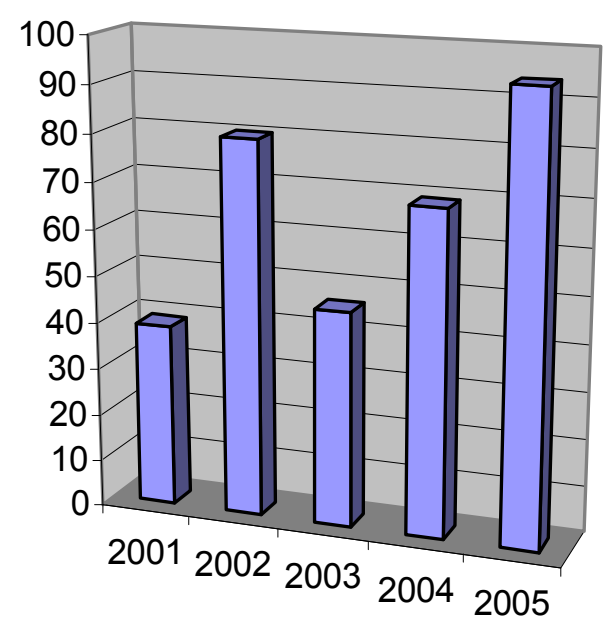

In 2005, students were surveyed to measure student attitudes about the use of computers in what otherwise are conventional in-class tests. The survey responses to 9 questions using a Likert scale are summarized on Table 1.

Two major conclusions of this survey are:

1. Engineering students overwhelmingly want to use spreadsheets during exams.

2. Students showed a preference for using of computer labs over using laptops for in-class tests. It can be speculated that this preference is the results from the inconvenience of using laptops in an ordinary classroom (need for power supplies, small desk space, etc).

Table 1

Results of Survey about the use of computers/laptops during in-class tests

(Numbers are percents)

\begin{tabular}{|c|c|c|c|c|c|c|}
\hline & & 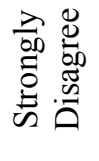 & 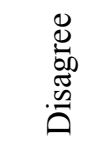 & z $\frac{\tilde{0}}{0}$ & 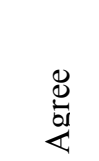 & 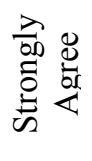 \\
\hline 1 & $\begin{array}{l}\text { I can solve some problems more quickly using a } \\
\text { spreadsheet than using a calculator }\end{array}$ & 4.2 & 12.5 & 8.3 & 25.0 & 50.0 \\
\hline 2 & $\begin{array}{l}\text { I think about calculations differently when I use a } \\
\text { laptop than when I use a calculator }\end{array}$ & 4.2 & 4.2 & 12.5 & 54.2 & 25.0 \\
\hline 3 & I make more mistakes when I use a calculator & 0.0 & 25.0 & 12.5 & 37.5 & 25.0 \\
\hline
\end{tabular}




\begin{tabular}{|l|l|c|c|c|c|c|}
\hline 4 & I do not like to use a computer. & 25.0 & 45.8 & 8.3 & 16.7 & 4.2 \\
\hline 5 & $\begin{array}{l}\text { Allowing the use of computers increases the } \\
\text { opportunity for cheating }\end{array}$ & 25.0 & 45.8 & 8.3 & 16.7 & 4.2 \\
\hline 6 & $\begin{array}{l}\text { Using a computer/laptop during in-class tests } \\
\text { makes the tests more like engineering practice. }\end{array}$ & 4.2 & 0.0 & 4.2 & 54.2 & 37.5 \\
\hline 7 & $\begin{array}{l}\text { Allowing students to use laptops during tests } \\
\text { favors students who can afford them }\end{array}$ & 4.2 & 16.7 & 45.8 & 25.0 & 8.3 \\
\hline 8 & $\begin{array}{l}\text { The use of computers during tests should be } \\
\text { allowed when the tests take place in a computer } \\
\text { laboratory. }\end{array}$ & 4.2 & 0.0 & 8.3 & 62.5 & 25.0 \\
\hline 9 & $\begin{array}{l}\text { The use of laptops during tests should be allowed } \\
\text { when the tests take place in a regular classroom. }\end{array}$ & 8.3 & 12.5 & 8.3 & 50.0 & 20.8 \\
\hline
\end{tabular}

$\mathrm{N}=25$

Additional statistical information can be obtained by using a chi square test to compare responses to pairs of questions. The chi square test measures the tendency for the response to one question to be related to the response to the second. This statistical test can be used to look for underlying trends in the responses to a survey. For this analysis the responses "agree" and "strongly agree" were combined into one group, as were "disagree and strongly disagree" to simplify the calculation.

This analysis indicated that there was a correlation between answers to question 6 and 8 at the $95 \%$ confidence level. Thus, students who favored using computers in tests also felt that computers "made tests more like engineering practice". There was also a correlation between questions 6 and 8 . The students who felt that they thought about problems differently when they used a laptop were likely to want to use that tool when they took a test. A reasonable inference from this conclusion is that some students might feel unfairly penalized if they prefer to use a spreadsheet and are forced to use calculators and interest tables. This result has obvious implications for the FE.

There was also a correlation between the responses for questions 5 and 7 . These are two question designed to elicit negative feelings about the use of computers during test. In both these questions about $20-25 \%$ indicated responses that could be interpreted as being negative toward the use of computers in-class. These questions show that there remains a fraction of students who have qualms about the use of computers in-class tests.

Finally, at the $95 \%$ confidence level there is a correlation between responses to question 1 ("I can solve some problems more quickly using a spreadsheet than using a calculator") and 2 ("I think about calculations differently when I use a laptop than when I use a calculator"). Students appear think that they approach problems differently depending upon the computational tool they 
are using. Furthermore, a majority appears to feel that they solve problems faster with a spreadsheet than with a calculator.

Several of the student observations can be summarized in one sentence. Students feel that using computers fundamentally and positively changes the way they approach calculations in engineering economics. The remainder of this paper discusses that assertion. First, I will present two common economic problems and discuss both calculator and spreadsheet solutions. Then, I will briefly summarize a theory of cognition that can be used to help understand these errors and lead to recommendations testing and teaching.

Consider the calculation of the present worth of the following cash flows at $15 \%$ interest rate ${ }^{1}$.

Figure 2

A series of cash flows

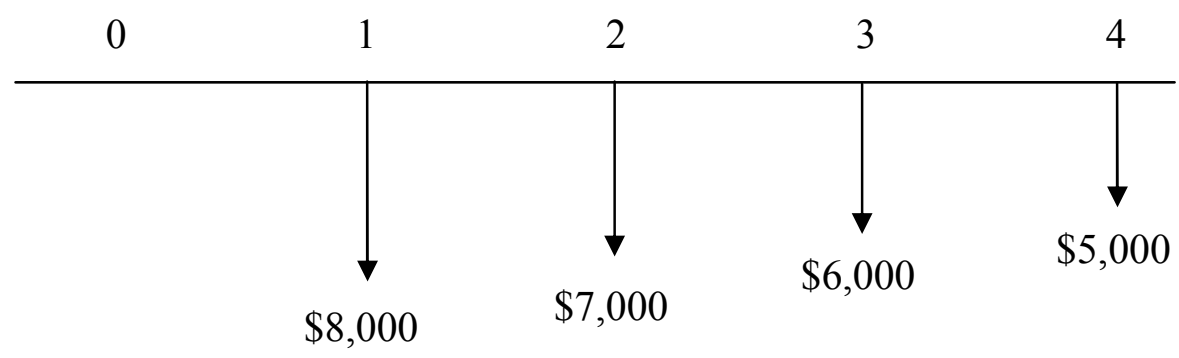

The solution provided in reference 1 involves separating the cash flow into two distinct cash flows: a uniform series of payments of $-\$ 8,000$, and a gradient of $\$ 1000$. Expressed mathematically, the present worth at time $\mathrm{t}=0$ is calculated by the equation

$$
\mathrm{P}=-\$ 8,000 \cdot(\mathrm{P} / \mathrm{A}, 15 \%, 4)+\$ 1,000 \cdot(\mathrm{P} / \mathrm{G}, 15 \%, 4)
$$

This solution involves separating the cash flows into two different streams whose present worths can be found using interest tables. To find a solution the student must recognize that the cash flows can be represented as the sum of cash flows for which tables exist. In short, the student must learn to see patterns in the cash flows.

Spreadsheet solution

A typical correct Excel spreadsheet solution is shown in Figure 3. The spreadsheet solution involves entering the values in a table and using the Excel function, NPV (which stands for Net Present Value). 
Figure 3

The Excel Solution to the Present Worth Problem

\begin{tabular}{|c|c|r|r|}
\hline \hline Microsoft Excel - Book1 \\
\hline
\end{tabular}

The same spreadsheet is shown in Figure 4 with the formulas visible.

Figure 4

The Formula used in the Excel Solution

\begin{tabular}{|c|c|c|c|c|}
\hline \multicolumn{5}{|c|}{ Microsoft Excel - Book1 } \\
\hline \multicolumn{2}{|c|}{ 国证 File } & Insert & Format Iools Data ! & Hel \\
\hline \multicolumn{5}{|c|}{ 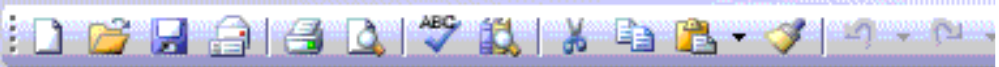 } \\
\hline \multicolumn{2}{|c|}{ E24 } & $f_{x}$ & & \\
\hline & A & & $\mathrm{B}$ & \\
\hline 1 & interest & & 0.15 & \\
\hline \multicolumn{5}{|l|}{2} \\
\hline 3 & Year & & Amount & \\
\hline 4 & 0 & & 0 & \\
\hline 5 & 1 & & -8000 & \\
\hline 6 & 2 & & -7000 & \\
\hline 7 & 3 & & -6000 & \\
\hline 8 & 4 & & -5000 & \\
\hline 9 & PW & & $=\mathrm{NPV}(\mathrm{B} 1, \mathrm{~B} 5: \mathrm{B} 8)+\mathrm{B} 4$ & \\
\hline 10 & & & & \\
\hline
\end{tabular}

In the spreadsheet solution it is not necessary for the student to recognize any pattern in the cash flows. The student merely enters numbers and correctly enters the NPV function. Essentially, the Excel solution uses equation 2.

$$
\mathrm{P}=\sum_{\mathrm{i}=0}^{\mathrm{n}} \mathrm{F}_{\mathrm{i}} \cdot(\mathrm{P} / \mathrm{F}, 15 \%, \mathrm{i})
$$

Doing the calculations with a calculator favors the use of equation 1 because that approach involves fewer table lookups. Using a spreadsheet favors equation 2 because that approach does not require looking for patterns and separating the cash flows into other cash flows. 
As teachers, we think about the errors that students make while doing these calculations. Students using a calculator are most prone to confusing the time for the start of the gradient cash flow. Another common error is reading the wrong line of a table. Students using a spreadsheet and the NPV function are most prone to incorrectly including year 0 in the function's argument list. An example of this kind of error would be for cell B9 in figure 4 to contain the formula NPV(B1, B4:B8).

Now, consider a second example: calculation of discounted payback time ${ }^{2}$

"A new process for manufacturing laser levels will have a first cost of $\$ 35,000$ with annual cost of $\$ 17,000$. Extra income associated with new process is expected to be $\$ 22,000$ per year. What is the payback period at $\mathrm{i}=10 \%$ ?"

The textbook's author recommends the following solution that uses a calculator and tables.

1. Calculate the $\mathrm{P} / \mathrm{A}$ ratio for the cash flows $(\$ 35,000 / \$ 22,000=1.5909)$

2. Find the two values of PA that bracket this value on the $10 \%$ interest table

3. Linearly interpolate to get $\mathrm{n}$

Using Excel, one alternative solution procedure is:

1. Use the Excel PV function to calculate the present value in a cell, include all data making the time period, $\mathrm{n}$, the value in another cell.

2. Use "solver" to drive the value in the "present value" cell to 0 by changing the value in the cell corresponding to $\mathrm{n}$ until the present value is 0 .

The spreadsheet solution is shown in Figure 5

Figure 5 


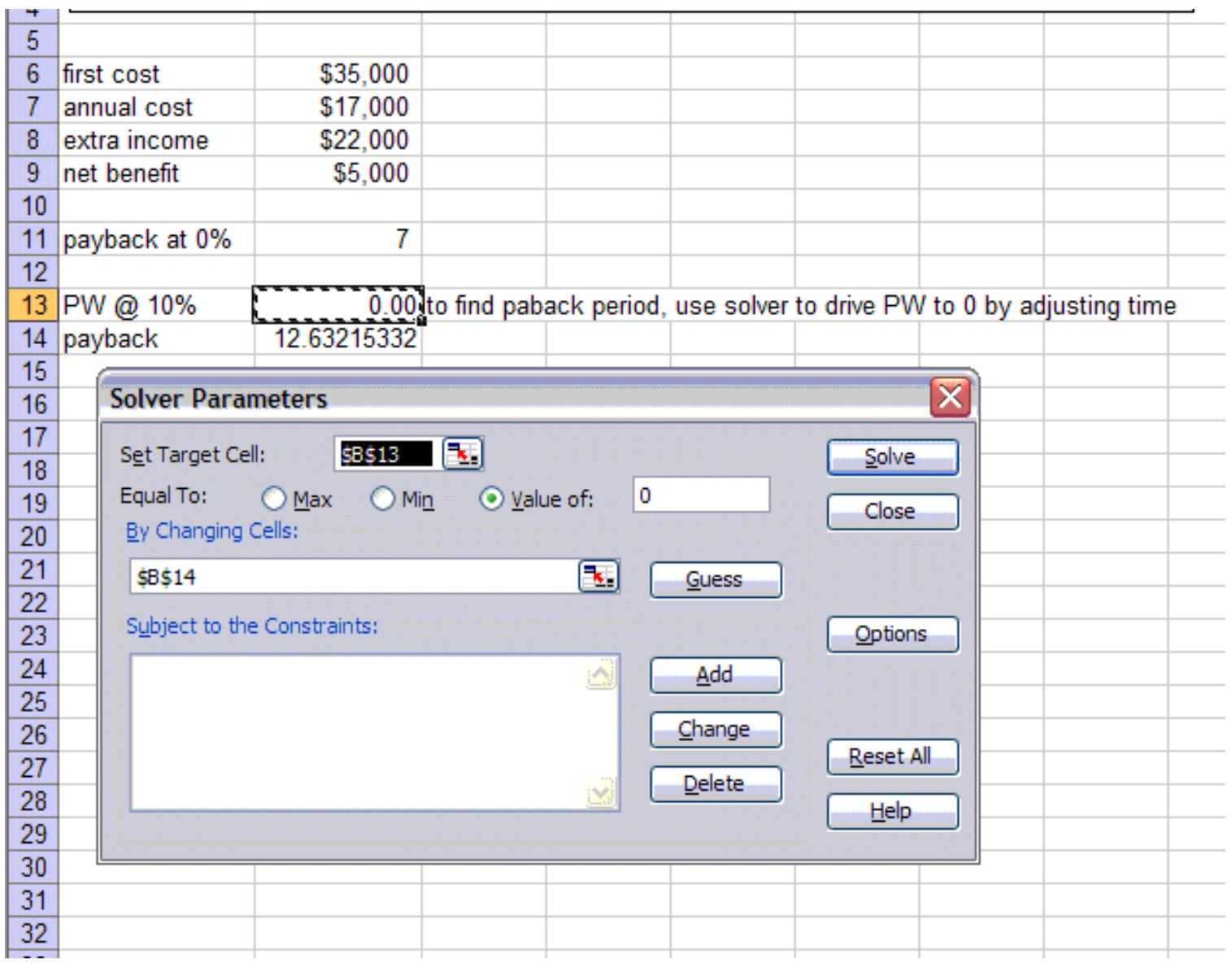

Although the spreadsheet solution can use the $\mathrm{P} / \mathrm{A}$ ratio as the objective function for solver, it is not necessary to use that ratio in this calculation. One can use present worth (or annual worth, or future value), just as easily. The key element of this solution procedure is the use successive approximations which is simplified by solver.

Although both procedures find the same value and solve the present worth equation, both methods use entirely different computational procedures. This example illustrates the ease with which successive approximations can be performed using Excel, and the tendency to avoid successive approximations when using a calculator. Thus, the computational tool (spreadsheet vs. calculator) determines the optimal solution procedure in spite of the underlying similarity in the theoretical approach. In order to accommodate both computational tools, both techniques were discussed in class.

These two examples show that:

1. spreadsheets can lead to different types of errors than calculators can lead to and,

2. the spreadsheet solution procedure may be different than the calculator solution procedure to the same problem. 
Students are correct when they say that they treat problems differently depending upon the tool they use.

\section{Dual Process theory}

Cognitive science, especially dual process theory $y^{3,4}$, can provide guidance when dealing with these differences between spreadsheet solutions and calculator solutions to engineering economic problems. Begin by noting that student errors can be grouped into two broad classes.

Class 1. Errors that depend on the computational tool the students use. These errors can be further broken down into:

1.1 Mechanical errors that do not reflect errors in understanding but are merely calculation errors or errors related to the usability of the interest tables (e.g. reading the wrong line on an interest table)

1.2 Programming errors including the wrong cell or group of cells in the argument list of a function

Class 2. Major conceptual errors: those mistakes which reflect faulty understanding of the problem itself or the general idea of the solution procedure. These mistakes occur regardless of the computational tools used. An example would be to ignore interest rate in the discounted payback calculation.

According to dual process theory, thought processes operate in two parallel and quite different modes often referred to as System 1 (S1) and System 2 (S2). These systems correspond quite roughly to our commonsense notions of intuition and analytical thinking. S1 processes are fast, automatic, effortless and often "done without thought". Because they are frequently habitual, they are often difficult to change. S2 processes, on the other hand, are slower, more thoughtful, requiring conscious effort and flexible. During the learning process, at least according to some theorists, new skills begin as S2 and move to S1.

An example of a skill that starts as S2 and becomes S1 is the act of driving an automobile. While learning to drive, the act of driving requires our full concentration and effort. After a while, the act of driving becomes more automatic and effortless. After some practice, we move, from having our full attention to keeping the car centered in our lane, monitoring the speed and traffic, etc, to being able to hold a conversation with a passenger, listen to the radio and "dividing our attention" to other matters. The transition occurs slowly and almost without notice. That the process of driving becomes habitual and automatic is proven by the common experience of people who generally drive manual transmission cars and then switch to an automobile with an automatic transmission. In a panic stop, these drivers often hit the floor with their left foot (an act that replicates the act of depressing the clutch when driving an automobile with a manual transmission, but is meaningless when driving an automobile with an automatic transmission).

During the processes of learning and problem solving, the two methodologies, S1 and S2 can be in conflict, causing surprising errors when learning science and mathematics. There are many examples of such mistakes in the literature on cognition. Such errors give insight into learning 
and thought processes. An example ${ }^{6}$ for the tendency of the fast reacting S1 one methodology, "hijack" the subject's attention and produce unusual answers is reproduced below:

\section{A baseball bat and ball cost together one dollar and 10 cents. The bat costs one dollar} more than the ball. How much does the ball cost?

Almost everyone reports an initial tendency to answer ' 10 cents' because the sum $\$ 1.10$ separates naturally into $\$ 1$ and 10 cents, and 10 cents is about the right magnitude. Frederick found that many intelligent people yield to this immediate impulse: $50 \%$ (47/93) of Princeton students, and 56\% (164/293) of students at the University of Michigan gave the wrong answer. (p. 451)

Dual-process theory treats these problems as a "cognitive illusions", similar to optical illusions. Students regard these kinds of problems as "trick questions". Certain features of cognitive illusions lead the S1 process to jump to an incorrect answer and override the slower and more thoughtful S2 process. In the baseball bat problem these features are that $\$ 1.00$ and 10 cents are explicitly mentioned and 10 cents is close to the right answer. The results of this work indicated that many people accepted the S1 answer and therefore "behaved irrationally". For others, their S1 thought processes jumped to the 10 cents but their S2 stopped them and they found the correct answer ${ }^{5}$.

The incorrect usage of the NPV function may be a "cognitive illusion". Most students entering engineering economics are already familiar with Excel, especially the use of such features as Solver. Therefore, these skills have passed from S2 (requiring thought) into S1 (habitual) for many of the students. But, most Excel functions require ALL the numbers in a series to be included. The NPV function does not require year 0 (it is often not included in tables of cash flows). Furthermore the use of NPV is probably new to most students in engineering economics. Teaching spreadsheet solutions requires emphasis on the correct use of the NPV function even though most students may already be familiar with Excel.

Using dual process theory, the S1 errors correspond to the tool dependent errors found in engineering economics tests. This probably explains why there was little difference in grades between the students using laptops and calculators. Errors such as reading the wrong line on a table or entering the incorrect value on a cell as "math errors" that have only a small penalty.

The discounted payback calculation indicates that the S2 thought processes are influenced by the computational tool because the tool determines the selection of an efficient computational approach. The aim of our school's engineering economics course was to teach the underlying economic concepts, an S2 skill, using whatever computational tool (spreadsheet vs. calculator) the preferred. Thus, the student select the tool for which he or she had the most S1 skills. Students who are already familiar with Excel's ability to perform successive approximations can more easily acquire the solver solution to the discounted payback than the calculator solution. Because some students each tool, the instruction includes both solution methods.

Conclusions 
1. Students can learn the underlying principles of engineering economics using either calculators or laptops. Many students have a preference for using spreadsheets while learning engineering economic sand are aware at a "gut level" that their thought process depend upon whether they are using a computer and spreadsheet or a calculator and tables.

2. Instruction needs to make students aware the of "cognitive illusions" associated with computations (I call them "bear traps").

3. It is possible to allow the use of computers, including student laptops in regular one hour examinations, although such use requires careful modification of the examination questions so that those not using a computer are on equal footing with those using a computer

4. Because the method of solution a problem depends on the tool used, students at our school are allowed to select the tool they wish to use while they are learning and being assessed in engineering economics. Students are being told that currently the FE allows only the calculator.

\section{References}

1. Sullivan, William G, Wickes, Ein M. and Luxhoj, James T, Engineering Economy 12th ed., Prentice-Hall, 2003

2. Blank, Leland and Tarquin, Anthony Egineering Economy, $6^{\text {th }}$ ed. McGraw Hill, 2005

3. Leron, U. (2005). Intuitive Vs. Analytical Thinking: Four Theoretical Frameworks, to be presented in CERME4 WG11, Sant Feliu de Guixols, Spain, February, 2005.

4. Leron, U. \& Hazzan, O. (accepted). The Rationality Debate: Application of Cognitive Psychology to Mathematics Education to appear in Educational Studies in Mathematics, revised 24.3.05.

5. Leron, U. (1987). Abstraction Barriers in Mathematics and Computer Science. Plenary Talk, the Third International Conference on Logo and Math Education (LME3), Montreal, Canada.

6. Kahnemann, D. (Nobel Prize Lecture, December 8): 2002, 'Maps of bounded rationality: A perspective on intuitive judgment and choice' in Les Prix Nobel

7. Emond, Bruno (1997) Cognitive Processes in Spreadsheet Comprehension, the Nineteenth Annual Conference in Cognitive Science Society (pp. 908) 